\title{
FITOSSANIDADE
}

\section{TRANSMISSIBILIDADE DO VÍRUS DA LEPROSE DE CERCAS-VIVAS, QUEBRA-VENTOS E PLANTAS DANINHAS PARA LARANJEIRAS ATRAVÉS DE BREVIPALPUS PHOENICIS (GEIJSKES) (1)}

\author{
OZANA MARIA DE ANDRADE MAIA ${ }^{(2,4)}$; CARLOS AMADEU LEITE DE OLIVEIRA ${ }^{(3)}$
}

\begin{abstract}
RESUMO
O ácaro Brevipalpus phoenicis (Geijskes) é transmissor do vírus da leprose dos citros, doença responsável por significativa redução da produtividade. Objetivou-se avaliar neste trabalho a possibilidade de algumas plantas utilizadas como cercas-vivas e quebra-ventos, além de plantas daninhas de pomares cítricos serem hospedeiras do vírus da leprose. O experimento foi realizado em laboratório e casa-devegetação na FCAV/UNESP, Jaboticabal-SP-Brasil. De uma criação-estoque de ácaros, criados sobre frutos de citros (Citrus sinensis) contendo lesões de leprose, foram transferidos 100 ácaros para uma unidade experimental das seguintes espécies: Hibiscus sp., Malvaviscus mollis, Grevillea robusta, Mimosa caesalpiniaefolia, Bixa orellana, Commelina benghalensis, Sida cordifolia, Ageratum conyzoides e Citrus sinensis, e mantidas em casa de vegetação por um período de 90 dias. Depois desse período, 160 ácaros foram recuperados dessas espécies vegetais e transferidos para quatro mudas das variedades cítricas 'Natal' e 'Valência' (20 ácaros / planta), e foram mantidas por 60 dias em casa de vegetação. Decorrido esse período, quantificou-se o número de lesões de leprose presentes nas folhas, ramos e caules das mudas cítricas. Em mudas cítricas da variedade 'Natal', foram observados sintomas da leprose decorrentes da transferência de ácaros provenientes de C. sinensis, A. conyzoides, C. benghalensis e B. orellana. Na variedade 'Valência', sintomas de leprose ocorreram em mudas infestadas com ácaros criados sobre C. sinensis, S. cordifolia benghalensis, B. orellana e A. conyzoides. Mudas cítricas das variedades 'Natal' e 'Valência' não manifestaram sintomas de leprose com ácaros procedentes de M. mollis, Hibiscus sp., G. robusta e M. caesalpiniaefolia.
\end{abstract}

Palavras-chave: vírus da leprose dos citros, ácaro vetor, plantas hospedeiras, transmissão, Citrus sinensis.

$\left.{ }^{1}\right)$ Recebido para publicação em 7 de junho de 2004 e aceito em 7 de junho de 2005.

$\left({ }^{2}\right)$ Faculdade de Ciências Agrárias e Veterinárias/UNESP, Via de Acesso Prof. Paulo Donato Castellane, s/nº, 14884-900 Jaboticabal (SP). E-mail: ozana_maia@yahoo.com.br

$\left({ }^{3}\right)$ Departamento de Fitossanidade, FCAV/UNESP. E-mail: amadeu@fcav.unesp.br

$\left({ }^{4}\right)$ Bolsista CAPES. 


\section{ABSTRACT \\ TRANSMISSION OF LEPROSIS VIRUS FROM HEDGE ROWS, WINDBREAKS AND WEEDS TO ORANGE TREES VIA BREVIPALPUS PHOENICIS (GEIJSKES)}

The mite Brevipalpus phoenicis (Geijskes) is a vector of the citrus leprosies virus, a disease that significantly reduces orange production. We examined whether some plant species used in hedgerows or as windbreaks, as well as various weeds found within the orchard, could serve as alternative hosts for the leprosis virus. This experiment was done in a greenhouse at FCAV/UNESP, Jaboticabal-SP-Brasil. One hundred mites were transferred from a stock colony, which was reared on citrus fruits (Citrus sinensis) that had leprosis lesions, to each of the following plant species: Hibiscus sp., Malvaviscus mollis, Grevillea robusta, Mimosa caesalpiniaefolia, Bixa orellana, Commelina benghalensis, Sida cordifolia, Ageratum conyzoides and Citrus sinensis. These artificially-infested plants were maintained in a greenhouse for 90 days. After this period, 160 mites were recovered from each of these plant species and were transferred to four small citrus trees of the varieties 'Natal' and 'Valência' (20 mites/plant). These were maintained for 60 days in a greenhouse. After this period, the number of leprosis lesions were counted on the leaves, branches and stems of the citrus trees. 'Natal' trees had leprosis symptoms when infested with mites from $C$. sinensis, A. conyzoides, C. benghalensis and B. orellana. 'Valência' trees were affected when infested with mites from C. sinensis, S. cordifolia, C. benghalensis, B. orellana and A. conyzoides. Neither of these citrus varieties was affected when infested with mites from M. mollis, Hibiscus sp., G. robusta, or M. caesalpiniaefolia.

Key words: citrus leprosis virus, mite vector, host plants, transmission, Citrus sinensis.

\section{INTRODUÇÃO}

A leprose dos citros, doença virótica cujo agente transmissor no Brasil é o ácaro Brevipalpus phoenicis (Geijskes), constitui sério problema para a citricultura brasileira, recrudescido nesses últimos anos, resultando em uma das principais doenças da cultura (ROSSETI, 2001), e reduzindo significativamente a produtividade das plantas cítricas, especialmente laranjeiras (Citrus sinensis Osbeck) (Musumesi e Rossetti, 1963; Chiavegato e Mischan, 1987).

Kitajima et al. (1972) examinaram, ao microscópio-eletrônico, secções ultrafinas de tecidos foliares de diversas variedades de laranjeira e de pomelo, com lesões de leprose; observaram, nas células do mesófilo, adjacentes ao tecido necrosado, a presença de partículas em formas de bastonetes, morfologicamente semelhantes às componentes internas de vírus baciliformes (rhabdovirus) de plantas, além de cloroplastos alterados, e sugeriram que a doença teria etiologia viral. Posteriormente, verificou-se que outro tipo de alteração celular, referente ao "tipo citoplasmático" era induzido pela leprose. Nesse, partículas baciliformes curtas ocorriam no retículo endoplasmático bem como viroplasma denso no citoplasma (KITAJIMA et al., 1974; Colariccio et al., 1995). Tem sido verificado que o tipo citoplasmático prevalece, sendo raros os casos do tipo nuclear, relatado em uma amostra em Santo Antônio da Posse, SP, Brasil (Kitajima et al.1972) e também ao norte do Panamá (Dominguez et al., 2000).
Chiavegato e Salibe (1986a) relataram que o ácaro B. phoenicis, uma vez infectado, não perde a capacidade de transmitir o vírus da leprose quando transferido de uma folha sadia para outra, pelo menos nos quatro primeiros dias de alimentação, e também, não é necessário o ácaro alimentar-se em uma lesão típica de leprose, bastando apenas alimentar-se em áreas onde, previamente, ácaros contaminados tenham se alimentado. Entretanto, essas partículas virais são vistas somente em tecidos com lesões de leprose e nunca em tecidos vegetais sem lesões (KiтAjIMA et al., 1972; COLARICCIO et al., 1995).

A ocorrência de partículas semelhantes a vírus nos tecidos foliares com lesões de leprose, mas não em áreas sadias adjacentes, indica um caráter aparentemente não sistêmico do vírus, ou seja, de localização restrita à extensão da lesão. Esse fato amplia de modo considerável a importância do vetor na epidemiologia da doença, uma vez que sua ocorrência é condição fundamental para a disseminação da doença dentro da planta e do pomar (COLARICCIO et al., 1995).

O ácaro vetor da leprose dos citros é uma espécie polífaga e tem ampla gama de hospedeiros alternativos nos pomares cítricos, os quais podem manter e/ou incrementar suas populações. Além disso, existe a possibilidade de essas plantas comportarem-se como hospedeiras do vírus, o que representa um risco muito grande para os pomares cítricos, aumentado sobremaneira a probabilidade de contaminação do ácaro e, conseqüentemente, a disseminação da leprose. 
Na busca pela redução da incidência desta doença em pomares cítricos, diversas táticas têm sido adotadas, visando a um controle integrado. Além do controle químico, sobressaem-se o uso de cercas-vivas e/ ou quebra-ventos adequados e o manejo correto das plantas daninhas. O uso de cercas-vivas e/ou quebraventos inadequados e um controle menos efetivo às plantas daninhas presentes nos pomares poderiam estar incrementando a fonte de inóculo e a disseminação da doença.

O objetivo deste trabalho foi de avaliar a capacidade de cercas-vivas e quebra-ventos mais utilizados em pomares cítricos, bem como as plantas daninhas mais freqüentes, constituírem-se em hospedeiras do vírus da leprose.

\section{MATERIAL E MÉTODOS}

Foram realizados experimentos em casa de vegetação e em laboratório, no período de julho a dezembro de 2001.

\subsection{Criação estoque de ácaros contaminados}

Foram utilizados ácaros provenientes de uma criação-estoque, mantida de acordo com método adotado por Chiavegato e Mischan (1987), a qual foi desenvolvida em frutos de laranja da variedade Pêrario, procedentes de pomares da região de Bebedouro, SP, com alta incidência de sintomas de leprose e altos níveis de infestação de ácaros, os quais, há vários meses, não haviam sido pulverizados com quaisquer agrotóxicos. Os frutos selecionados apresentavam sintomas de leprose e verrugose, dada a preferência do ácaro por frutos com superfície rugosa (Albuquerque et al., 1997).

Em laboratório, os frutos foram submetidos a uma máquina de varredura "Modelo Jaboticabal" (Oliveira, 1983), para a retirada de possíveis outros ácaros e insetos e, a seguir, receberam uma fina camada de parafina deixando-se uma área circular de três $\mathrm{cm}$ de diâmetro, sem parafina na parte lateral do fruto. As áreas continham sintomas de verrugose para o pleno desenvolvimento dos ácaros e lesões de leprose, para garantir sua contaminação. Para impedir a fuga dos ácaros, as áreas foram delimitadas com uma barreira adesiva de 'Tanglefootâ'.

Os frutos foram dispostos em bandejas plásticas e mantidos em câmara climatizada sob temperatura de $25 \pm 1{ }^{\circ} \mathrm{C}$, umidade relativa de $60 \pm$ $5 \%$ e fotofase de 14 horas.
A criação-estoque foi revigorada, de tempos em tempos, com ácaros da mesma procedência. Os frutos, em início de deterioração, foram substituídos por novos frutos.

A transferência dos ácaros foi efetuada pela justaposição desses aos novos frutos, com as mesmas características anteriormente mencionadas.

\subsection{Transmissibilidade do vírus da leprose das cer- cas-vivas, quebra-ventos e plantas daninhas para citros através de $B$. phoenicis}

Para esse estudo, desenvolveu-se um experimento em casa-de-vegetação, em que se adotou um delineamento estatístico de blocos casualizados, onde nove tratamentos foram repetidos quatro vezes e dispostos em prateleiras $(3,0 \mathrm{~m} \times 2,0 \mathrm{~m})$.

Utilizaram-se as seguintes espécies de cercasvivas ou quebra-ventos: hibisco (Hibiscus sp. L.), malvavisco (Malvaviscus mollis DC.), grevílea (Grevillea robusta A. Cunn.), sansão-do-campo (Mimosa caesalpiniaefolia Benth.) e urucum (Bixa orellana L.). Três espécies de plantas daninhas foram testadas: trapoeraba (Commelina benghalensis L.), guanxuma (Sida cordifolia L.) e mentrasto (Ageratum conyzoides L.), que são freqüentes em pomares cítricos da região e, com exceção da trapoeraba, as demais são citadas como hospedeiras do ácaro em diversas regiões do Estado de São Paulo (TRINDAde, 1994). Como controlepadrão da transmissão, utilizaram-se mudas cítricas da variedade Pêra-rio.

Essas plantas foram formadas no Horto Florestal da FCAV/UNESP Jaboticabal (SP), empregando-se as práticas culturais normalmente adotadas para as espécies e, posteriormente, transplantadas para vasos, contendo partes iguais de terra, areia e esterco curtido.

Cada planta foi podada a fim de reduzir sua área foliar (4 folhas/muda) para facilitar o manuseio e transplantadas para vasos. Em seguida, foram desinfestadas com o auxílio de um pincel e algodão umedecido. Na base de todas as plantas, próximo à superfície do solo, aplicou-se uma barreira adesiva, de Tanglefoot ${ }^{\circledR}$ com o objetivo de impedir a fuga de ácaros, bem como a entrada de predadores. Posteriormente, cada planta foi infestada com 100 ácaros contaminados, procedentes da criação-estoque. Das plantas utilizadas, somente a trapoeraba é uma planta com hábito rasteiro ou trepador; assim cada planta dessa espécie recebeu um suporte de madeira, previamente isolado com Tanglefoot ${ }^{\circledR}$ em sua base, para se fixar de acordo com seu desenvolvimento. 
Em seqüência, as plantas foram levadas à casa de vegetação e mantidas distanciadas cerca de $1 \mathrm{~m}$ para evitar contato entre folhas, onde permaneceram durante 90 dias, tempo suficiente para que ocorressem dois ciclos biológicos do ácaro. Esse tempo é superior à longevidade do adulto, assegurando-se, assim, a ausência dos ácaros inicialmente transferidos, pois segundo НARAMOTO (1969), a longevidade de B. phoenicis, a uma temperatura de $25^{\circ} \mathrm{C}$, é de 44 dias.

Após esse período, em laboratório essas plantas foram repicadas e submetidas à máquina de varredura para a recuperação dos ácaros. Dentre esses, os adultos mais ativos presentes na placa de vidro do equipamento foram retirados (mínimo de 180 ácaros), e posteriormente transferidos para oito mudas cítricas formadas no horto do Fundo de Defesa da Citricultura (FUNDECITRUS). Essas foram previamente podadas e preparadas com barreira adesiva, de Tanglefoot ${ }^{\circledR}$ com o objetivo de impedir a fuga de ácaros, bem como a entrada de predadores. Utilizaram-se quatro mudas de cada variedade cítrica, 'Natal' e 'Valência', no total de 20 ácaros/muda.

Uma vez infestadas, as mudas cítricas foram levadas à casa de vegetação, onde permaneceram durante 60 dias, distanciadas uma das outra, com o objetivo de evitar contatos. Os dados relativos à temperatura e umidade foram registrados diariamente através de um termo-higrômetro. Os valores médios foram calculados de acordo com a fórmula universal (outubro $64,6 \pm 18,8 \%$ e $23,2 \pm 4,8{ }^{\circ} \mathrm{C}$, novembro $69,9 \pm 14,3 \%$ e $28,6 \pm 7,1^{\circ} \mathrm{C}$ e dezembro $68,8 \pm 10,5$ e 28,4 $\pm 7,8^{\circ} \mathrm{C}$ ), tendo sido considerados favoráveis ao bom desenvolvimento dos ácaros.

Findo o período de 60 dias, quantificou-se o número de lesões de leprose em folhas e ramos das mudas cítricas variedades 'Valência' e 'Natal', com a finalidade de verificar quais, dentre as cercas-vivas, quebra-ventos e plantas daninhas, se comportam como hospedeiras do vírus da leprose.

Os dados relativos às contagens de lesões de leprose foram transformados em $\sqrt{x+0,5}$ com a finalidade de normalização, para serem analisados pelo teste F, e as médias comparadas pelo teste Tukey, a $5 \%$ de probabilidade.

\section{RESULTADOS E DISCUSSÃO}

O aparecimento de lesões nas mudas cítricas iniciou-se por volta do vigésimo dia após a infestação, como já observado por Chiavegato e Salibe (1986b), que verificaram aparecimento da maioria das lesões de leprose após 17-20 dias da inoculação do vírus através da alimentação do acarino.

O número de lesões de leprose observado nas mudas cítricas da variedade 'Valência' com ácaros $B$. phoenicis transferidos de mudas cítricas variedade 'Pêra-rio', inicialmente infestados com ácaros contaminados, foi superior ao número de lesões constatadas com ácaros criados sobre mentrasto, urucum, sansão-do-campo, hibisco, malvavisco e grevílea; todavia, não diferiu do número de lesões com ácaros procedentes de trapoeraba e guanxuma (Tabela 1). Ácaros transferidos de guanxuma, mentrasto, urucum e trapoeraba para mudas cítricas da variedade 'Valência' acarretaram números de lesões de leprose que não diferiram entre si. Mudas cítricas da variedade 'Valência' com ácaros provenientes de sansão-docampo, hibisco, malvavisco e grevílea não manifestaram sintomas de leprose, sendo constatada total ausência de lesões; todavia, não diferiram quanto ao número de lesões, daquelas cujos ácaros foram criados sobre urucum, mentrasto e trapoeraba.

Na variedade 'Natal', verificaram-se lesões de leprose nas mudas cítricas cujos ácaros provieram de mudas cítricas de 'Pêra-rio', trapoeraba, mentrasto e urucum. Nas mudas cítricas infestadas com ácaros criados sobre guanxuma, sansão-do-campo, hibisco, malvavisco e grevílea não ocorreu nenhuma lesão de leprose. Somente naquelas com ácaros criados sobre urucum observaram-se números reduzidos de lesões, que não diferiram das anteriores, sem lesões.

Considerando-se ambas as variedades Valência e Natal - verifica-se uma tendência de ocorrer maior número de lesões de leprose nessas variedades com ácaros provenientes de mudas cítricas de Pêrario, embora não tenham sido detectadas diferenças, no caso de 'Valência', para ácaros oriundos de guanxuma e trapoeraba, e enfocando-se 'Natal', para ácaros provenientes de mentrasto e trapoeraba.

Chiavegato e Salibe (1986b) verificaram que o ácaro B. phoenicis adquire o agente causal de leprose após alimentar-se por dois dias em folhas que previamente serviram de alimento para ácaros de pomares contaminados durante quatro dias. Uma vez que o urucum pode hospedar o vírus da leprose, não deve ser recomendado como cerca-viva e/ou quebravento nos pomares cítricos, bem como as plantas daninhas trapoeraba, guanxuma e mentrasto, que devem ser radicalmente eliminadas dos pomares cítricos, já que hospedam o ácaro, bem como o vírus da leprose dos citros. 
Tabela 1. Número médio (+EPM) de lesões de leprose em folhas e ramos de citros das variedades 'Valência' e 'Natal', avaliadas 60 dias após a permanência de ácaros Brevipalpus phoenicis, criados em diferentes espécies hospedeiras. Jaboticabal (SP), 2001

\begin{tabular}{|c|c|c|}
\hline \multirow{2}{*}{ Espécies hospedeiras de B. phoenicis } & \multicolumn{2}{|c|}{ N. ${ }^{\circ}$ de lesões de leprose } \\
\hline & Valência & Natal \\
\hline Trapoeraba (C. benghalensis) & $5,0 \pm 1,9 \quad \mathrm{~A} a b c$ & $5,5 \pm 2,6 \quad \mathrm{~A} \mathrm{ab}$ \\
\hline Guanxuma (S. cordifolia) & $8,5 \pm 3,0 \quad \mathrm{~A} \mathrm{ab}$ & $0,0 \pm 0,0 \quad \mathrm{~B} \mathrm{~b}$ \\
\hline Mentrasto (A. conyzoides) & $3,2 \pm 2,0 \quad \mathrm{~A} \mathrm{bc}$ & $5,5 \pm 2,2 \quad \mathrm{~A} \mathrm{ab}$ \\
\hline Sansão do campo (M.caesalpiniaefolia) & $0,0 \pm 0,0 \quad \mathrm{~A} \mathrm{C}$ & $0,0 \pm 0,0 \quad \mathrm{~A} \mathrm{~b}$ \\
\hline Urucum (B. orellana) & $3,7 \pm 2,2 \quad \mathrm{~A} \mathrm{bc}$ & $2,5 \pm 1,4 \quad \mathrm{~A} \mathrm{~b}$ \\
\hline Hibisco (Hibiscus sp.) & $0,0 \pm 0,0 \quad \mathrm{~A} \mathrm{c}$ & $0,0 \pm 0,0 \quad \mathrm{~A} \mathrm{~b}$ \\
\hline Malvavisco (M. mollis) & $0,0 \pm 0,0 \quad \mathrm{~A} \mathrm{C}$ & $0,0 \pm 0,0 \quad \mathrm{~A} \mathrm{~b}$ \\
\hline Grevílea (G. robusta) & $0,0 \pm 0,0 \quad \mathrm{~A} \mathrm{c}$ & $0,0 \pm 0,0 \quad \mathrm{~A} \mathrm{~b}$ \\
\hline Laranjeira Pêra-rio (C. sinensis) & $13,5 \pm 2,5 \mathrm{~A} \mathrm{a}$ & $12,5 \pm 0,9 \mathrm{~A} \mathrm{a}$ \\
\hline Média & $3,8 \pm 0,9 \quad \mathrm{~A}$ & $2,9 \pm 0,7 \quad \mathrm{~A}$ \\
\hline
\end{tabular}

Médias seguidas da mesma letra maiúscula na linha e minúscula na coluna não diferem significativamente entre si, pelo teste de Tukey $(P \geq 0,05)$.

\section{CONCLUSÕES}

1. Em mudas cítricas da variedade 'Natal', são observados sintomas da leprose em decorrência da transferência de ácaros provenientes de $C$. sinensis (variedade Pêra-rio), A. conyzoides, C. benghalensis e $B$. orellana.

2. Em mudas cítricas da variedade 'Valência', os sintomas de leprose ocorrem quando ácaros criados sobre $C$. sinensis (variedade Pêra-rio), $S$. cordifolia, C. benghalensis, B. orellana e A. conyzoides são transferidos para elas.

3. Mudas cítricas das variedades 'Natal' e 'Valência' não manifestam sintomas de leprose com ácaros procedentes de M. mollis, Hibiscus sp., G. robusta e M. caesalpiniaefolia.

\section{AGRADECIMENTOS}

À Coordenação de Aperfeiçoamento de Pessoal de Nível Superior (CAPES) pela concessão da bolsa de mestrado e ao Fundo de Defesa da Citricultura (FUNDECITRUS), pelo suporte técnico.

A Reinaldo Aparecido Longo, do Laboratório de Acarologia (FCAV-UNESP).

\section{REFERÊNCIAS}

ALBUQUERQUE, F. A.; OLIVEIRA, C. A.; BARRETO, M. Estudos da relação entre as incidências de verrugose da laranjadoce e leprose dos citros em frutos de laranja-pêra. Científica, São Paulo, v.25, n.2, p.393-402. 1997.
CHIAVEGATO, L. G; SALIBE, A. A. New results on the transmissibility of leprosis symptoms by mite Brevipalpus phoenicis in citrus. In: CONFERENCE OF INTERNATIONAL ORGANIZATION OF CITRUS VIROLOGISTS, 10., 1986. Valência. Proceedings... Riverside: IOVC, 1986. p.136.

CHIAVEGATO, L. G; SALIBE, A. A. Prejuízos provocados pelo ácaro Brevipalpus phoenicis (Geijskes, 1939) (Acari: Tenuipalpidae) em frutos de diferentes variedades cítricas. In: CONGRESSO BRASILEIRO DE FRUTICULTURA, 6., 1986, Recife. Anais... Recife: Sociedade Brasileira de Fruticultura, 1986. p.709-718.

CHIAVEGATO, L.G.; M.M. MISCHAN. Comportamento do ácaro Brevipalpus phoenicis (Geijskes, 1939) (Acari: Tenuipalpidae) em frutos de diferentes variedades cítricas. Científica, Jaboticabal, v.15, p.17-22, 1987.

COLARICCIO, A.; LAVISSOLO O.; CHAGAS, C. M.; GALLETI, S. R.; ROSSETTI, V.; KITAJIMA, E. W. Mechanical transmission and ultrastructural aspects of citrus leprosis virus. Fitopatologia Brasileira, Brasília, v. 20, p. 208-213. 1995.

DOMINGUEZ, F. S.; BANDEL, A.; CHILDERS, G.; KITAJIMA, E. W. Leprose dos citros no Panamá. Summa Phytopathologica, Botucatu, v. 26, p. 132, 2000.

HARAMOTO, F. M. H. Biology and control of Brevipalpus phoenicis (Geijskes) (Acarina: Tenuipalpidae). Honolulu: Hawaii Agricultural Experiment Station, 1969. 61 p. (Technical Bulletin, 68)

KITAJIMA, E. W.; MÜLLER G. W.; COSTA A. S.; YURI V. A. Short rod like particles associated with citrus leprosis. Virology, Orlando, v.50, p.254-258, 1972.

KITAJIMA, E. W.; ROSILLO, M. A; PORTILLO, M. A; MULLER, G.; COSTA, A. S. Microscopia eletrônica de tecidos foliares de laranjeiras infectadas pela lepra explosiva da Argentina. Fitopatologia, Lima, v. 9, p. 55-56. 1974. 
MUSUMECI, M. R.; ROSSETTI, V. Transmissão dos sintomas da leprose dos citros pelo ácaro Brevipalpus phoenicis. Ciência e Cultura, São Paulo, v.15, n.228, 1963.

OLIVEIRA, C. A. L. Máquina de varredura de ácaro Modelo Jaboticabal. Anais da Sociedade Entomológica do Brasil, Piracicaba, v. 12, p.299-303. 1983.
ROSSETTI, V. V. Manual ilustrado de doenças do citros. 1. Ed. Piracicaba: Fealq/Fundecitrus, 2001. 207 p.

TRINDADE, M.L.B.; CHIAVEGATO, L. G. Caracterização biológica dos ácaros, Brevipalpus obovatus D., 1875, B. californicus B., e B. phoenicis G. (Acari: Tenuipalpidae). Anais da Sociedade Entomológica do Brasil, Piracicaba, v. 23, p.189-195. 1994. 